\title{
Physicochemical, microbial, and sensory properties of nanopowdered eggshell-supplemented yogurt during storage
}

\author{
Mohammad Al Mijan, Kyung-Hoon Choi, and Hae-Soo Kwak ${ }^{1}$ \\ Department of Food Science and Technology, Sejong University, Seoul 143-747, Korea
}

\begin{abstract}
This study was carried out to investigate the possibility of adding nanopowdered eggshell (NPES) into yogurt to improve the functionality of yogurt and the effects of adding NPES on the physicochemical, microbial, and sensory properties of the products during storage. The $\mathrm{pH}$ and mean lactic acid bacteria counts of NPES-added (0.15-0.45\%, wt/vol) yogurt ranged from 4.31 to 4.66 and from $6.56 \times 10^{8}$ to $8.56 \times 10^{8}$ $\mathrm{cfu} / \mathrm{mL}$, respectively, whereas these values ranged from 4.13 to 4.44 and $8.46 \times 10^{8}$ to $1.39 \times 10^{9}$, respectively, for the control samples during storage at $5^{\circ} \mathrm{C}$ for 16 $\mathrm{d}$, which indicates a prolonged shelf-life with NPESsupplemented yogurt. Color analysis showed that the lightness $\left(\mathrm{L}^{*}\right)$ and position between red and green $\left(\mathrm{a}^{*}\right)$ values were not significantly influenced by the addition of NPES. However, the position between yellow and blue $\left(b^{*}\right)$ value significantly increased with the addition of the concentration $(0.45 \%$, wt $/ \mathrm{vol})$ of NPES at $d$ 16 of storage. Sensory evaluation revealed that NPESadded yogurts showed a notably less sourness score and a higher astringency score than the control. An earthy flavor was higher in $0.45 \%$ NPES-supplemented yogurt compared with the control. Based on the results obtained from the current study, the concentration (0.15 to $0.30 \%$, wt/vol) of NPES can be used to formulate NPES-supplemented yogurt without any significant adverse effects on the physicochemical, microbial, and sensory properties.
\end{abstract}

Key words: nanopowdered eggshell, functional yogurt, shelf-life

\section{INTRODUCTION}

Eggshell contains about 39\% elemental Ca and the bioavailability of eggshell $\mathrm{Ca}$ is as high as that from $\mathrm{CaCO}_{3}$ (Schaafsma and Beelen, 1999). As it is widely available, it can be a cheap and effective solution for a large number of Ca-deficient populations. The benefi-

Received August 14, 2013.

Accepted March 1, 2014.

${ }^{1}$ Corresponding author: kwakhs@sejong.ac.kr cial effects of eggshell on bone mineral density of the skeletal system have been demonstrated in postmenopausal women (Makai and Chudáček, 1991; Schaafsma and Pakan, 1999). Eggshell also has some other nutrients, such as $\mathrm{Mg}, \mathrm{P}$, glycoproteins, and proteoglycans (Hincke, 1995; Hincke et al., 1999). The protein matrices that are present in eggshell are regarded to be involved in the mineralization process through their calcium-binding properties (Daengprok et al., 2003). It is of interest to know that chicken eggshell powder also contains $\mathrm{Sr}$ (380 mg/g, on average) and this micronutrient may have an anabolic effect on bone metabolism (Reginster et al., 1999). Surprisingly, this precious Ca source is currently considered as a waste product after breaking operations in egg-processing plants. A huge amount of eggshell is disposed of as landfill, giving rise to environmental pollution. However, upon the discovery of the positive effects of eggshell on human health, great demand exists for comprehensive research on improving the edibility and bioavailability of eggshell to be used in food products. In this regard, nanotechnology can be an effective and viable solution, as it has numerous applications in enhancing the biocompatibility of several food ingredients.

Nanotechnology is a new and emerging technique to be used in the food and pharmaceutical industries for promoting physical and biological properties, including solubility and stability. It has the potential to improve the food system in various ways; particularly, it is believed that nanosizing increases the bioavailability of the micro- and micronutrients present in food products. The enhancement of bioavailability of Ca through nanosizing has been reported recently by several studies (Park et al., 2008; Seo et al., 2009; Hilty et al., 2011). An ever-increasing trend exists in the food industry of developing food products supplemented with nanosized nutritional elements. Yogurt is one of the few potential food products in the market that are widely used as vehicles to supplement functional ingredients for mass population.

Yogurt is a dairy product manufactured through the lactic acid fermentation of milk and is popularly consumed throughout the world. It is recognized as a healthy food for containing a large amount of nutri- 
tional elements, including calcium. A well-known fact about calcium is that this mineral is an essential constituent of the human body and a large daily intake is necessary. According to the Institute of Medicine, an individual has to take 1,000 to $1,200 \mathrm{mg}$ of calcium on a daily basis. It is well accepted that dietary calcium intake has never been sufficient and, for that reason, dietary intervention through the supplementation of calcium in foods is suggested to meet the requirement. Generally, the calcium content in commercial yogurt is limited to $332 \mathrm{mg}$ per serving $(175 \mathrm{~mL})$. As a consequence, efforts have been made to supplement purified $\mathrm{CaCO}_{3}$ in yogurt (Ramasubramanian et al., 2008). But the applicability of purified $\mathrm{Ca}$ in yogurt is still limited due to having undesirable side effects and low bioavailability. It is recommended that $\mathrm{Ca}$ should be taken from biological sources. In this regard, eggshell can be a cheap, easily obtainable but plentiful source of $\mathrm{Ca}$ for food applications. However, no report exists in the literature on the production of a nanopowdered eggshell (NPES)-added yogurt. Therefore, this study was carried out to develop health-promoting yogurt with added nanopowdered eggshell and to examine the effects of this addition on the physicochemical and sensory properties of yogurt.

\section{MATERIALS AND METHODS}

\section{Materials}

Commercial milk was purchased from Seoul Dairy Coop. (Seoul, Korea). Nanopowdered and micropowdered eggshells were procured from Apexel Co. (Pohang, Korea). Agar powder was obtained from Showa Chemical Co. (Tokyo, Japan). Difco lactobacilli de Man, Rogosa, and Sharpe (MRS) broth was bought from Becton, Dickinson and Co. (Detroit, MI). All chemicals used in this experiment were of analytical grade.

\section{Particle Size Analysis}

Size and morphological characteristics of NPES and powdered eggshell (PES) were observed using fieldemission scanning electron microscopy (SEM; S-4300; Hitachi Ltd., Tokyo, Japan). Each sample was spread on the surface of a stub with double-stick carbon tape. After sputtering with white gold for 120, the samples were examined by SEM operated at an accelerating voltage of $15.0 \mathrm{kV}$. The crystal shapes and sizes of NPES were determined using a transmission electron microscope (JEM-2010; JEOL Ltd., Tokyo, Japan). For transmission electron microscopy study, the sample was prepared on Formvar film-coated grids and was measured with an electron microscope operating at 100 $\mathrm{kV}$ accelerating voltage.
For analyzing the particle size distribution, $0.1 \mathrm{~g}$ of NPES was dispersed into $10 \mathrm{~mL}$ of ethanol. The suspension was then treated in a Branson 3210 ultrasonic system (Triad Scientific Inc., Manasquan, NJ) for 30 min and kept at room temperature for $10 \mathrm{~min}$. After pretreatment, the suspension was poured into a cuvette and the particle size was measured by using a particle size analyzer (DelsaNano C; Beckman Coulter Inc., Fullerton, CA) under specified conditions of $25^{\circ} \mathrm{C}$ and $160^{\circ}$ scattering angle. The particle size distribution of PES was determined by another instrument (Mastersizer 2000; Malvern Instruments Ltd., Worcestershire, UK) at $25^{\circ} \mathrm{C}$ and $90^{\circ}$ scattering angle. Each treatment was done in triplicate.

\section{Preparation of NPES- and PES-Supplemented Yogurts}

Yogurts were manufactured following the modified procedure of Seo et al. (2009). Milk was first standardized adding nonfat milk powder $(3.7 \%$, wt/vol) and pectin $(0.2 \%$, wt/vol; Kanto Chemical, Tokyo, Japan). Three different concentrations $(0.15,0.3$, and $0.45 \%$, wt/vol) of nano- and micropowdered eggshells were added to the milk. The milk was then homogenized at 1,200 $\mathrm{rpm}$ for $10 \mathrm{~min}$ with the laboratory-scale blender (MS3040 electronic overhead stirrer; Tops Misung Scientific Co., Seoul, Korea). The homogenized milk was heat treated at $90^{\circ} \mathrm{C}$ for $10 \mathrm{~min}$ and cooled down to approximately 42 to $43^{\circ} \mathrm{C}$. Commercial starter culture $(0.002 \%$ wt/vol; Sacco srl, Cadorago, Italy) in freezedried direct-to-vat set form containing Lactobacillus bulgaricus, Streptococcus thermophilus, and Bifidobacterium bifidum was added immediately and incubated at $43^{\circ} \mathrm{C}$ for approximately $6 \mathrm{~h}$. Yogurt samples were kept at $10^{\circ} \mathrm{C}$ for $24 \mathrm{~h}$ for stabilizing. The samples were then stored at $5^{\circ} \mathrm{C}$ in a refrigerator to evaluate the physicochemical and sensorial properties on d 0, 4, 8, 12, and 16 of storage. Each batch of yogurt making was done in triplicate.

\section{pH}

The $\mathrm{pH}$ value of each sample was measured with a waterproof digital pen-type $\mathrm{pH}$ meter $(\mathrm{pH}-222$; Lutron Electronics Co. Inc., Coopersburg, PA). All samples were measured in triplicate and the results were calculated as the mean value.

\section{Viscosity}

The viscosities of the samples $(50 \mathrm{~mL})$ were measured at room temperature using a Brookfield viscometer (model LVDV-I+, version 3.0; Brookfield, Stonington, 
MA) equipped with spindle no. 3, mixing at $60 \mathrm{rpm}$ for $5 \mathrm{~min}$. The viscosity was recorded every minute and all samples were measured in triplicate.

\section{Lactic Acid Bacteria}

The agar media was prepared by combining the powder MRS broth and $0.004 \%$ bromophenol blue (Sigma Aldrich, Germany) for lactic acid bacteria (LAB) counting. One milliliter of each yogurt sample was diluted with $9 \mathrm{~mL}$ of sterile $0.8 \% \mathrm{NaCl}$. Subsequent dilutions of each sample were plated in triplicate and incubated at $37^{\circ} \mathrm{C}$ for $48 \mathrm{~h}$.

\section{Color}

Color values of each yogurt sample were investigated using a colorimeter (CR210; Minolta, Tokyo, Japan) after calibrating its original value with a standard plate $(\mathrm{X}=97.83, \mathrm{Y}=81.58$, and $\mathrm{Z}=91.51)$. Measured $\mathrm{L}^{*}$, $\mathrm{a}^{*}$, and $\mathrm{b}^{*}$ values were used as indicators of lightness, redness, and yellowness, respectively. All samples were measured in triplicate.

\section{Sensory Analysis}

The sensory evaluation of control and NPES-supplemented yogurt was performed with 10 judges selected from graduate students of the Department of Food Science and Technology at Sejong University (Seoul, Korea). Three 1-h training sessions were held. At the end of the session, sensory attributes were established: 2 appearance attributes, 5 flavor and taste attributes, and 2 texture attributers. Standards used to define these flavor and taste descriptors were present during training and sensory evaluation.

Before each session, commercial plain yogurt was presented to familiarize the assessors with the sensory properties of the yogurt. The judges scored each attribute on a scale of 0 to 7 , in which 7 was the highest intensity and 0 was none. Samples were stored at $7^{\circ} \mathrm{C}$ before assessment. In each session, the order of assessment of the sample was randomized. The scores of each sample were averaged over all assessors. The sensory evaluation was performed in duplicate.

\section{Statistical Analysis}

All statistical analyses were performed using SAS (version 9.0; SAS Institute Inc., Cary, NC). An ANOVA was performed using the general linear models procedure to determine the significant differences among the samples. Means were compared by using the Fisher least significant difference procedure. Significance was defined at the $5 \%$ level.

\section{RESULTS AND DISCUSSION}

\section{Particle Size Analysis}

The morphology of NPES and PES was observed by SEM as shown in Figure 1. The SEM images demonstrated that the particle size of PES apparently decreased during the manufacture of NPES. The average particle sizes of PES and NPES measured were about 20 to $200 \mu \mathrm{m}$ by SEM and about 100 to $200 \mathrm{~nm}$ in diameter by the particle size analyzer, respectively (Figures 1 and 2).

\section{pH}

The changes in $\mathrm{pH}$ of yogurts supplemented with various concentrations of NPES are presented in Figure 3. All yogurt samples went through gradual decreases in $\mathrm{pH}$ during the storage period. Eggshell-supplemented yogurts exhibited higher $\mathrm{pH}$ values than the control.
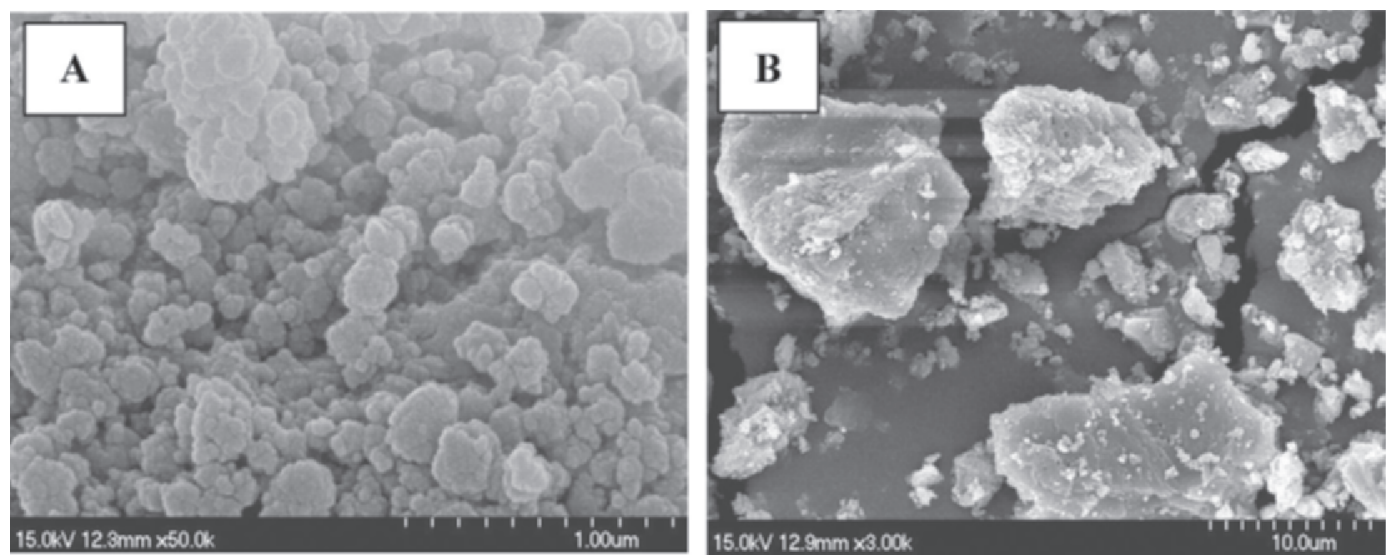

Figure 1. Scanning electron microscopy micrographs of (A) nanopowdered and (B) powdered eggshells. 

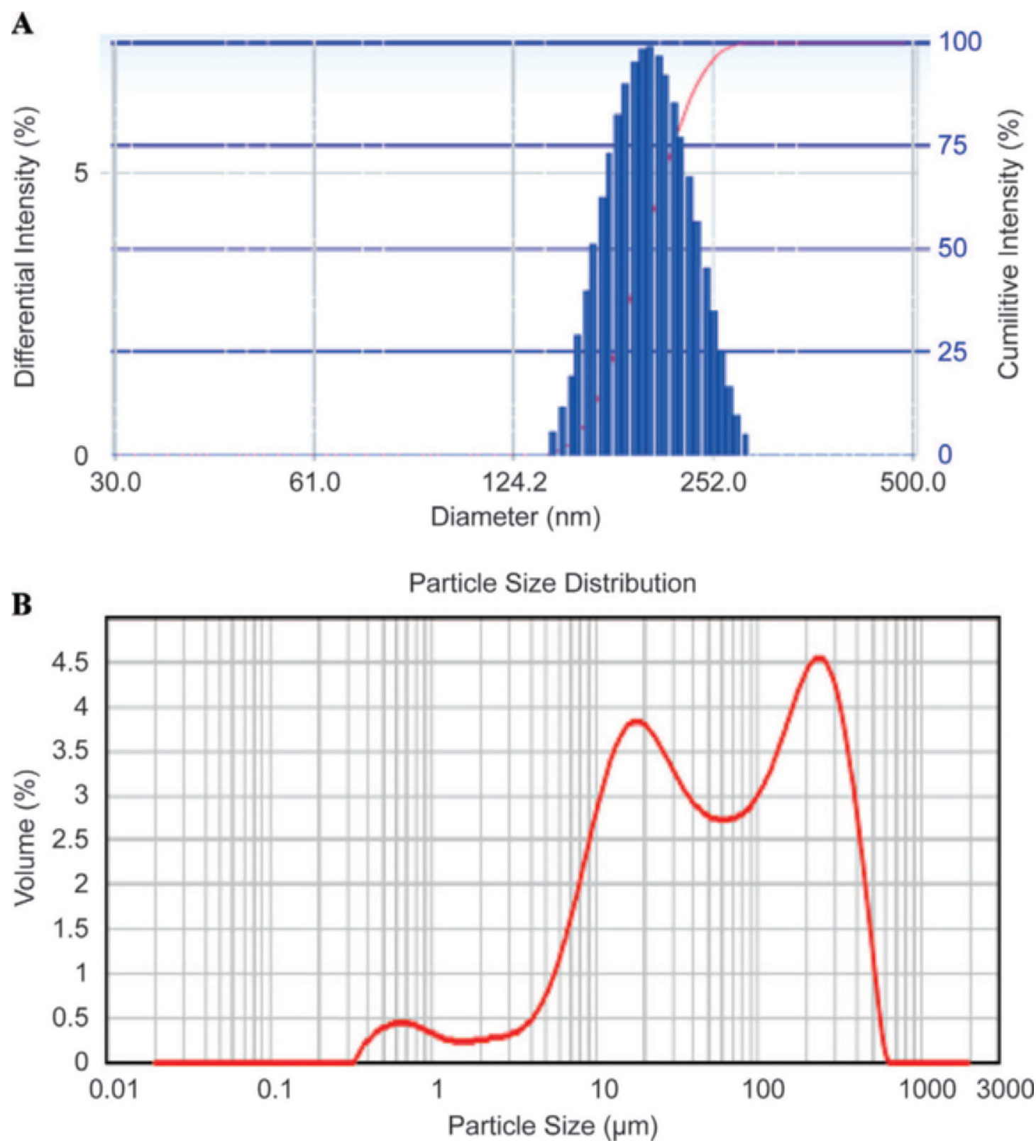

Figure 2. Particle size distributions of (A) nanopowdered and (B) powdered eggshells. Color version available in the online PDF.

The $\mathrm{pH}$ values in NPES- and PES-supplemented yogurts ranged from 4.31 to 4.66 and 4.23 to 4.53 , respectively, whereas in the control yogurt it ranged from 4.15 to 4.44 throughout the storage time. However, $\mathrm{pH}$ in NPES-supplemented yogurts remained higher than both PES-supplemented and control yogurts throughout the period. Increasing the concentrations $(0.15$, 0.3 , and $0.45 \%$, wt $/ \mathrm{vol}$ ) of NPES and PES in yogurts resulted in an increase in the $\mathrm{pH}$ value. In the study of Pirkul et al. (1997), different concentrations of Ca salts were added to yogurt and it was found that the
Ca-supplemented yogurts had significantly higher $\mathrm{pH}$ values than the control yogurt. Furthermore, the higher concentrations of $\mathrm{Ca}$ salt in the yogurt resulted in a higher $\mathrm{pH}$ value. It turns out that the buffering activity of the Ca salts present in the eggshell probably contributed to the higher values of the PES-supplemented yogurts. Relatively greater $\mathrm{pH}$ values in the NPES-supplemented yogurts than the PES-supplemented ones can be attributed to the higher buffering capacity of $\mathrm{Ca}$ salts present in NPES obtained from nanosizing. Based on the analysis of the $\mathrm{pH}$ values, it can be speculated 
Table 1. Changes in lactic acid bacteria ${ }^{1}(\mathrm{cfu} / \mathrm{mL})$ in nanopowdered eggshell (NPES)- or powdered eggshell (PES)-supplemented yogurt stored at $5^{\circ} \mathrm{C}$ for $16 \mathrm{~d}$

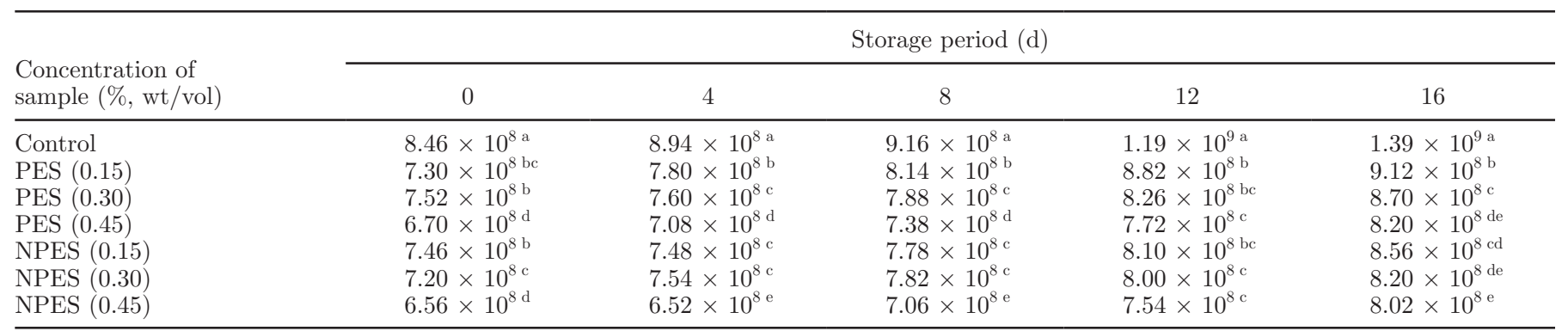

${ }^{\mathrm{a}-\mathrm{e}}$ Values with different superscript letters within a column are significantly different $(P<0.05)$.

${ }^{1}$ A mixture of Lactobacillus bulgaricus, Streptococcus thermophilus, and Bifidobacterium bifidum.

that adding NPES has a substantial effect in increasing the shelf-life of yogurt.

\section{$L A B$}

The changes in L. bulgaricus, S. thermophilus, and B. bifidum counts in NPES- or PES-supplemented yogurt samples stored at $5^{\circ} \mathrm{C}$ for $16 \mathrm{~d}$ are presented in Table 1. On the initial storage day, the mean LAB count of the control was significantly higher $(P<0.05)$ than those of NPES- or PES-supplemented yogurt samples. Moreover, increasing the concentrations of NPES and PES $(0.15-0.45 \%, \mathrm{wt} / \mathrm{vol})$ on d 0 of storage resulted in a reduction in the mean LAB population from $7.30 \times$ $10^{8}$ to $6.70 \times 10^{8} \mathrm{cfu} / \mathrm{mL}$ and from $7.46 \times 10^{8}$ to $6.56 \times$ $10^{8} \mathrm{cfu} / \mathrm{mL}$, respectively. This finding can be explained by the fact that eggshell powder, being enriched with a high level of $\mathrm{CaCO}_{3}$, had antimicrobial properties. The LAB content in the NPES-supplemented yogurt was a little lower than that of PES-supplemented yogurt. However, on d 16 of storage, the LAB count in all yogurt samples, including the control, was increased. Comparatively lower $\mathrm{pH}$ at the later part of the storage could be explained by promoted growth of LAB in the yogurts. Increase in LAB populations in Dioscorea opposita Thumb.-supplemented yogurts at the later part of the storage period was also reported by Kim et al. (2011). A recent study revealed that nano-calcium had negative effects on bacterial growth (Ataee et al., 2011). The antimicrobial effects of NPES supplementation were found to restrict the growth of LAB in yogurts in the current study. However, LAB populations were not noticeably diminished in the NPES-supplemented yogurts. Therefore, it can be concluded that NPESsupplemented yogurt could have a prolonged shelf-life beyond $16 \mathrm{~d}$.

\section{Viscosity}

The effect of NPES addition on the viscosity of yogurt during $16 \mathrm{~d}$ of storage is shown in Figure 4. On the initial day, the viscosities of the yogurts were increased when the concentration of NPES was increased. The PES-supplemented yogurts also had the same trend but the viscosities of the NPES-supplemented yogurts were relatively higher than their counterparts. On d 4 of storage, viscosities in all yogurt samples were slightly increased. Sahan et al. (2008) reported that due to the rearrangement of the protein molecules, the viscosity of yogurt might increase during storage. However, on the final day of storage, the viscosities of all samples, including the control, had decreased considerably. The decrease in viscosity might have been caused by the whey separation with increasing storage time. Noticeably, throughout the entire storage time, the viscosities in the NPES-supplemented yogurts remained higher than the yogurts supplemented with PES.

The additions of NPES or PES caused the enrichment of $\mathrm{CaCO}_{3}$ in yogurts, and higher concentrations of these 2 substances resulted in higher proportions of $\mathrm{CaCO}_{3}$ in the yogurt samples. The increased $\mathrm{CaCO}_{3}$ content increased the formation of calcium phosphate crosslinks within casein micelles. Singh and Muthukumarappan (2008) reported that Ca-enriched fruit yogurts were shown to have stronger structures. The firmness of Ca-enriched yogurts has been attributed to the colloidal calcium phosphate crosslinking between casein micelles caused by the increased $\mathrm{Ca}$ content. The result of the current study is in accordance with the findings of Singh and Muthukumarappan (2008). Higher viscosities in the NPES-supplemented yogurts can be explained by the fact that the finer particles of NPES allowed it to disperse well in yogurt and led to more calcium phosphate crosslinking in casein micelles to elevate the viscosities.

\section{Color Analysis}

The changes in color in the NPES- and PES-supplemented yogurts stored at $5^{\circ} \mathrm{C}$ for $16 \mathrm{~d}$ are presented in Table 2 . The $\mathrm{L}^{*}$ values were not significantly affected 


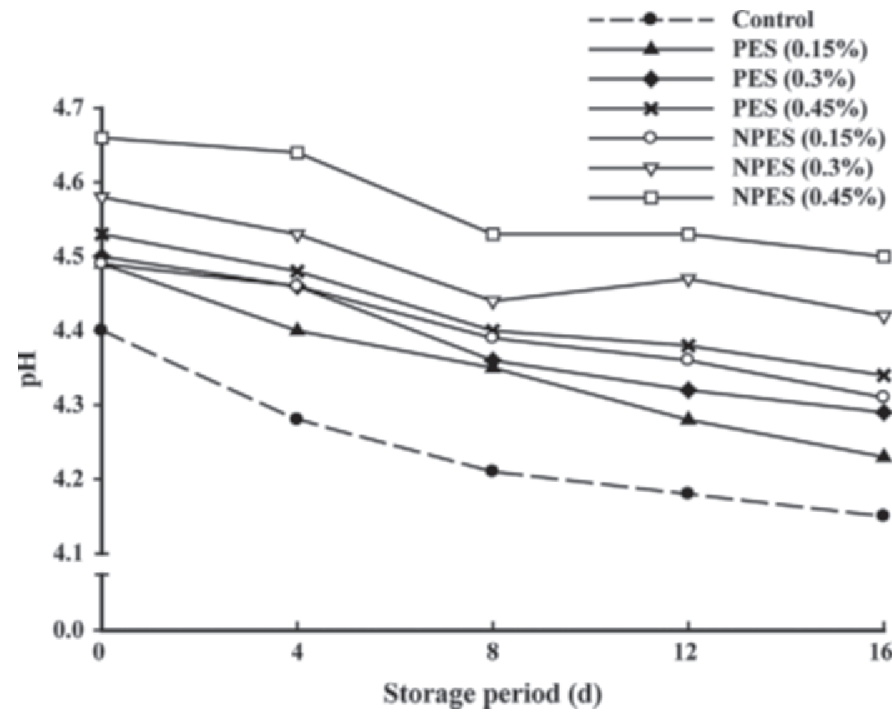

Figure 3. Changes in the $\mathrm{pH}$ of yogurts supplemented with nanopowdered and powdered eggshells during $16 \mathrm{~d}$ of storage at $5^{\circ} \mathrm{C}$. At d 0 , the yogurts had been stabilized for $24 \mathrm{~h}$. PES = powdered eggshells; NPES = nanopowdered eggshells.

by the addition of NPES and PES on the initial day $(P<0.05)$. Only the yogurt sample containing PES $(0.15 \%$, wt $/ \mathrm{vol})$ had an exceptionally lower $\mathrm{L}^{*}$ value than the others. The $\mathrm{L}^{*}$ values in yogurt samples, including the NPES-supplemented ones, were considerably increased during the $16 \mathrm{~d}$ of storage. The greatest change was noticed in PES $(0.15 \%$, wt/vol), where the $\mathrm{L}^{*}$ value increased from 86.90 to 89.03 . No noticeable changes were observed in the $a^{*}$ and $b^{*}$ values of

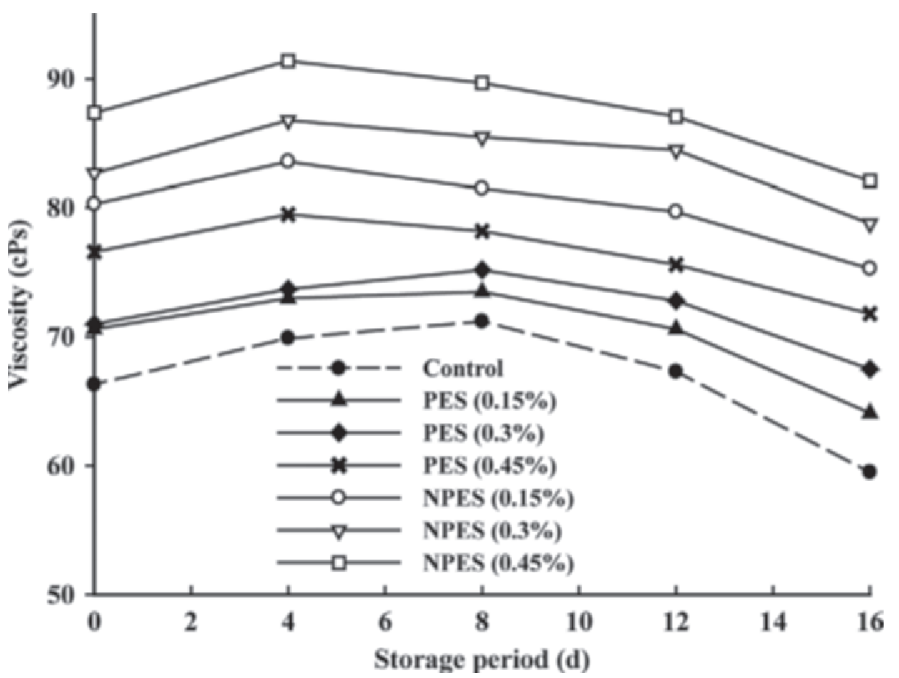

Figure 4. Changes in the viscosities of the yogurts supplemented with nanopowdered eggshells during $16 \mathrm{~d}$ of storage at $5^{\circ} \mathrm{C}$. PES $=$ powdered eggshells; NPES = nanopowdered eggshells.

NPES-supplemented and other yogurt samples, except in PES (0.15\%, wt/vol)-supplemented yogurt, where it was found that the $\mathrm{a}^{*}$ and $\mathrm{b}^{*}$ values increased from 7.20 to 7.66 and 9.64 to 10.66 , respectively.

\section{Sensory Evaluation}

The sensory properties of NPES- and PES-supplemented yogurts during $16 \mathrm{~d}$ of storage are shown in Table 3. Appearance, taste, flavor, and texture were

Table 2. Changes of color in nanopowdered eggshell (NPES)- or powdered eggshell (PES)-supplemented yogurt stored at $5^{\circ} \mathrm{C}$ for $16 \mathrm{~d}$

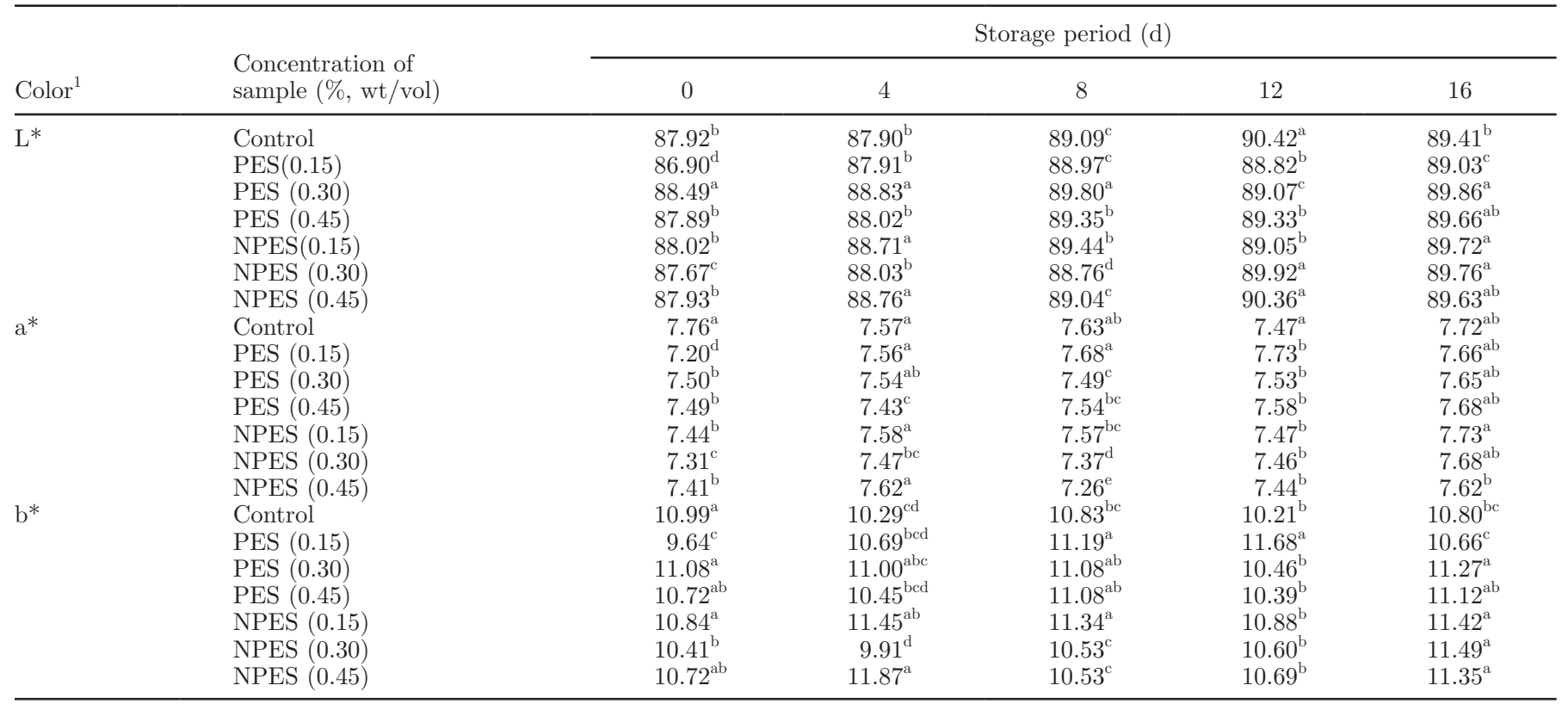

${ }^{\mathrm{a}-\mathrm{e}}$ Values with different superscript letters within a column are significantly different $(P<0.05)$.

${ }^{1} \mathrm{~L}^{*}, \mathrm{a}^{*}$, and $\mathrm{b}^{*}$ values are indicators of lightness, redness, and yellowness, respectively. 
Table 3. Sensory characteristics ${ }^{1}$ for nanopowdered eggshell (NPES)- or powdered eggshell (PES)-supplemented yogurt stored at $5^{\circ} \mathrm{C}$ for $16 \mathrm{~d}$

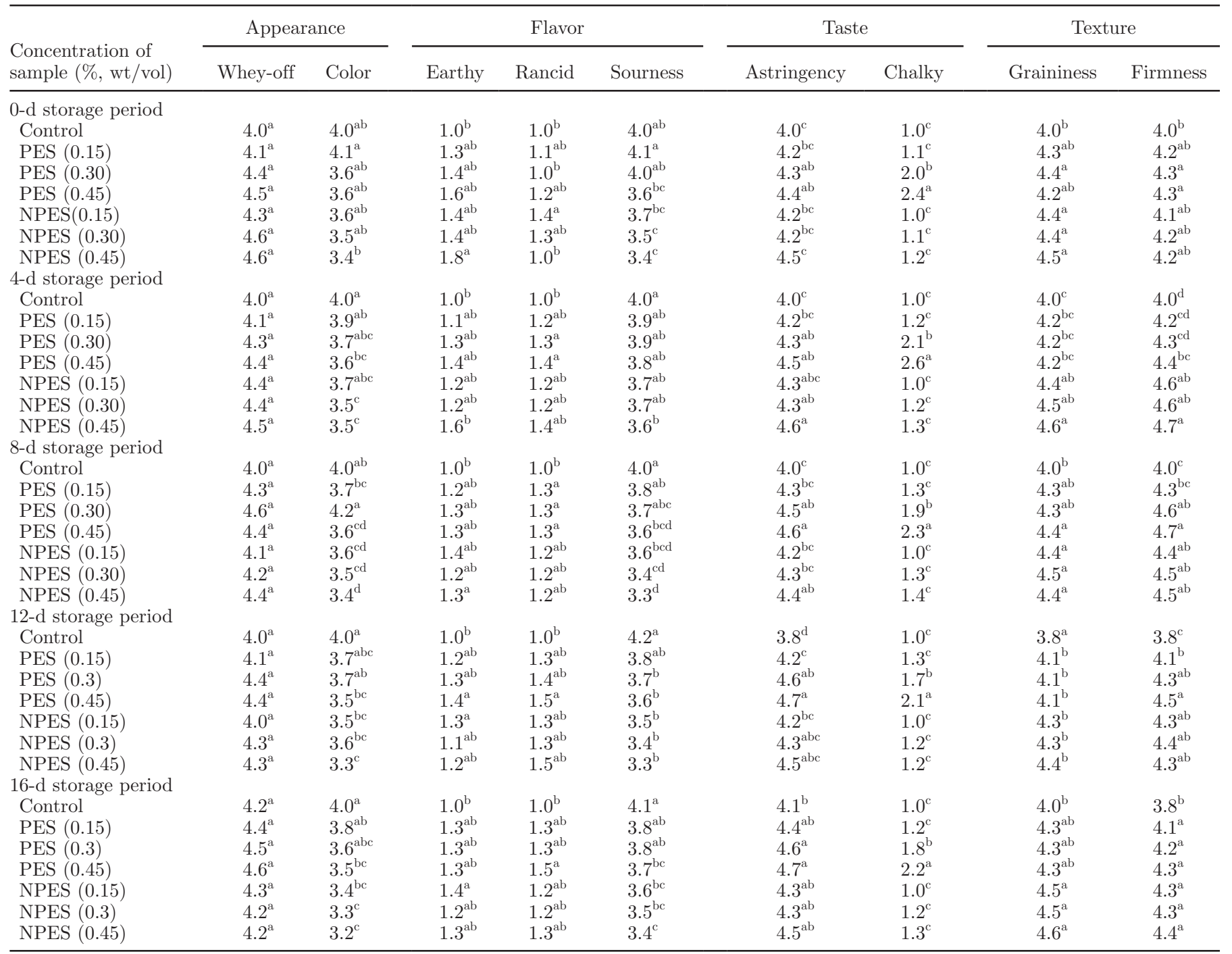

${ }^{\mathrm{a}-\mathrm{d}}$ Values with different superscript letters within a column are significantly different $(P<0.05)$.

${ }^{1}$ Scale of appearance, flavor, taste, and texture scores: $1=$ very weak, $4=$ moderate, and $7=$ strong.

analyzed during the storage period. The whey-off score did not significantly change during the storage time $(P$ $>0.05)$. On the initial day, the $b^{*}$ score decreased with the increasing concentration of NPES and PES (0.15, 0.3 , and $0.45 \%$, wt $/ \mathrm{vol}$ ), due to the dark white color of the eggshell powder. Rancidity was not increased in the NPES- and PES-supplemented yogurts; however, the earthy flavor only was significantly increased in the yogurts supplemented with NPES and PES $(P<0.05)$. The high amount of $\mathrm{Ca}$ in the eggshell powder might have added the earthy flavor in the yogurts. Sourness was decreased by the addition of NPES and PES. The astringency score was increased in both NPES- and PES-supplemented yogurts. The most distinguishable attribute of the eggshell powder was chalkiness, which was found considerably higher in the yogurts supplemented with PES. The chalkiness in the NPES-supplemented yogurts on the other hand was not significant $(P>0.05)$, mostly because of the fine granular sizes of the NPES. The ultra-fine granules of NPES in the yogurts were not strongly felt by the panelists, except for a little chalky taste $(0.45 \%$ NPES). Both graininess and firmness were found to increase in the NPES- and PES-supplemented yogurts. It was assumed that NPES and PES, being solid particles, were responsible for giving the yogurts grainier and firmer texture. Singh and Muthukumarappan (2008) reported that the fruit yogurts enriched with $\mathrm{Ca}$ were not different from the control in terms of appearance, flavor, texture, and overall acceptability. Based on the data obtained from in the 
current study, we suggest that NPES $(0.15$ and $0.3 \%$, $\mathrm{wt} / \mathrm{vol}$ ) can be added to produce NPES-supplemented yogurt.

\section{CONCLUSIONS}

This study was undertaken to develop NPES-supplemented yogurt and to see the changes in the physicochemical, microbial, and sensory properties of yogurts upon the addition of NPES during storage at $5^{\circ} \mathrm{C}$ for 16 $\mathrm{d}$. The resulting data on $\mathrm{pH}$, viscosity, $\mathrm{LAB}$, color, and sensory evaluation from this study suggested that the supplementation of NPES did not show any adverse effect on the yogurt quality. Therefore, we conclude that NPES (0.15 and $0.3 \%$, wt/vol) could be applicable to the manufacture of functional yogurt.

\section{ACKNOWLEDGMENTS}

The present study was supported by a grant from the Korea Institute of Planning and Evaluation for Technology in Food, Agriculture, Forestry and Fisheries (Gyeonggi-Do, Republic of Korea).

\section{REFERENCES}

Ataee, R. A., J. Derakhshanpour, A. Mehrabi Tavana, and A. Eydi. 2011. Antibacterial effect of calcium carbonate nanoparticles Agrobacterium tumefaciens. Iranian J. Military Med. 13:65-70.

Daengprok, W., W. Garnjanagoonchorn, O. Naivikul, P. Pornsinlpatip, K. Issigonis, and Y. Mine. 2003. Chicken eggshell matrix proteins enhance calcium transport in the human intestinal epithelial cells, Caco-2. J. Agric. Food Chem. 51:6056-6061.

Hilty, F. M., J. T. N. Knijnenburg, A. Teleki, F. Krumeich, R. F. Hurrell, S. E. Pratsinis, and M. B. Zimmermann. 2011. Incorporation of $\mathrm{Mg}$ and $\mathrm{Ca}$ into nanostructured $\mathrm{Fe}_{2} \mathrm{O}_{3}$ improves Fe solubility in dilute acid and sensory characteristics in foods. J. Food Sci. $76: \mathrm{N} 2-\mathrm{N} 10$.

Hincke, M. T. 1995. Ovalbumin is a component of the chicken eggshell matrix. Connect. Tissue Res. 31:227-233.

Hincke, M. T., J. Gautron, C. P. W. Tsang, M. D. McKee, and Y. Nys. 1999. Molecular cloning and ultrastructural localization of the core protein of an eggshell matrix proteoglycan, ovocleidin-116. J. Biol. Chem. 274:32915-32923.

Kim, S. H., S. Y. Lee, G. Palanivel, and H. S. Kwak. 2011. Effect of Dioscorea opposita Thunb. (yam) supplementation on physicochemical and sensory characteristics of yogurt. J. Dairy Sci 94:1705-1712.

Makai, F., and J. Chudáček. 1991. The treatment of osteoporosis with Biomin-H. Arch. Gerontol. Geriatr. 2:487-490.

Park, J.-W., S.-R. Bae, J.-Y. Suh, D.-H. Lee, S.-H. Kim, H. Kim, and C.-S. Lee. 2008. Evaluation of bone healing with eggshell-derived bone graft substitutes in rat calvaria: A pilot study. J. Biomed. Mater. Res. A 87:203-214.

Pirkul, T., A. Temiz, and Y. K. Erdem. 1997. Fortification of yoghurt with calcium salts and its effect on starter microorganisms and yoghurt quality. Int. Dairy J. 7:547-552.

Ramasubramanian, L., C. Restuccia, and H. C. Deeth. 2008. Effect of calcium on the physical properties of stirred probiotic yogurt. J. Dairy Sci. 91:4164-4175.

Reginster, J.-Y., V. Halkin, Y. Henrotin, and C. Gosset. 1999. Treatment of osteoporosis: Role of bone-forming agents. Osteoporos. Int. 9(Suppl. 2):S91-S96.

Sahan, N., K. Yasar, and A. A. Hayaloglu. 2008. Physical, chemical and flavour quality of non-fat yogurt as affected by a $\beta$-glucan hydrocolloidal composite during storage. Food Hydrocoll. 22:12911297.

Schaafsma, A., and G. M. Beelen. 1999. Eggshell powder, a comparable or better source of calcium than purified calcium carbonate: Piglet studies. J. Sci. Food Agric. 79:1596-1600.

Schaafsma, A., and I. Pakan. 1999. Effect of a chicken egg shell powder enriched dairy product on bone mineral density in persons with osteoporosis or osteopenia. Nutrition 15:157.

Seo, M. H., S. Y. Lee, Y. H. Chang, and H. S. Kwak. 2009. Physicochemical, microbial, and sensory properties of yogurt supplemented with nanopowdered chitosan during storage. J. Dairy Sci. 92:5907-5916.

Singh, G., and K. Muthukumarappan. 2008. Influence of calcium fortification on sensory, physical, chemical and rheological characteristics of fruit yogurt. Lebenson. Wiss. Technol. 41:1145-1152. 